\title{
NBSIR 84-3005
}

\section{THE NBS WR62 and WR90 REFERENCE NOISE STANDARDS}

National Bureau of Standards U.S. Department of Commerce Boulder, Colorado 80303

May 1984 



\section{THE NBS WR62 and WR90 REFERENCE NOISE STANDARDS}

C.K.S. Miller

W.C. Daywitt

Electromagnetic Fields Division

National Engineering Laboratory

National Bureau of Standards

U.S. Department of Commerce

Boulder, Colorado 80303

May 1984

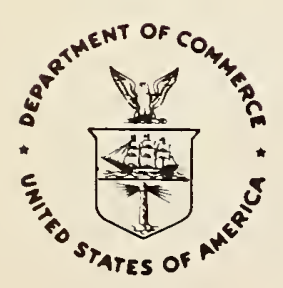

U.S. DEPARTMENT OF COMMERCE, Malcolm Baldrige, Secretary

NATIONAL BUREAU OF STANDARDS, Ernest Ambler, Director 

Abstract

1. THE BASIS FOR A REFERENCE NOISE STANDARD . . . . . . . . . . . . . . . . 1

1.1 Requirements of a Reference Standard . . . . . . . . . . . . . . . . . . 4 4

2. THE WR9O AND WR62 REFERENCE NOISE STANDARDS . . . . . . . . . . . . . . 4

2.1 Fundamentals . . . . . . . . . . . . . . . . . . . . . . . 4 4

2.1.1 Transmission Line Effects . . . . . . . . . . . . . . 4

2.1 .2 Resistor Design . . . . . . . . . . . . . 6

2.1 .3 Oven Design . . . . . . . . . . . . . . . . . . . 6

2.2 Application to the WR90 and WR62 Reference Standards . . . . . . . . . . 9

2.2.1 The Waveguide Transmission Line . . . . . . . . . . . . . 9

2.2.2 The Microwave Resistor. . . . . . . . . . . . . . . . 11

2.2.3 Accuracy of the WR90 Standard . . . . . . . . . . . . . 11

3. COMPARISON OF REFERENCE STANDARDS . . . . . . . . . . . . . . . . . 13

3.1 International Comparison with Sweden . . . . . . . . . . . . . . . . 14

3.2 International Comparison with England . . . . . . . . . . . . . 15

3.3 International Comparison with Australia and Japan. . . . . . . . . . . 16 APPENDIX. NOISE TEMPERATURE DERIVATION . . . . . . . . . . . . . . . 20 



\section{K. S. Miller and W. C. Daywitt \\ National Bureau of Standards \\ Boulder, Colorado 80303}

The basis for the National Bureau of Standards (NBS) WR90 and WR62 Waveguide Reference Noise Standards and the corresponding error analyses are described. The standards are heated $(1270 \mathrm{~K}$ ) thermal noise generators, and a derivation of their output noise temperature equations is also presented. Results of comparisons of the NBS WR90 standard with those of Sweden, England, Australia, and Japan are included. The text is extracted from course notes presented at NBS in 1970, and hence does not include descriptions of standards constructed at NBS since that time.

Key words: error analysis; international comparisons; microwave; noise standard.

\section{THE BASIS FOR A REFERENCE NOISE STANDARD}

Temperature as a measure is one of the six internationally agreed upon Basic Standards [1] defined by concerted agreement of the member nations to the treaty signed and known as the Metric Convention; the other five are, "the meter" (defined in terms of the wavelength of krypton light - 86), "the second" (defined in terms of a transition of the cesium atom), "the kilogram" (defined in terms of a cylindrical mass of platinum-irridium alloy and kept at the International Bureau of Weights and Measures in Paris), "the ampere" (defined in terms of the magnetic field induced between two parallel wires separated by one meter), and "the candela" (defined in terms of the intensity of light radiated from a cavity maintained at the temperature of freezing platinum). The thermodynamic or kelvin scale of temperature used in the International System of Units (SI), has its origin or zero point at absolute zero and has a fixed point at the triple point of water defined as 273.16 kelvins. The Celsius and Fahrenheit scales are derived from the kelvin scale, and the triple point of water in each of these is respectively $0.01^{\circ} \mathrm{C}$ and $32.02^{\circ} \mathrm{F}$.

According to the international System of Units, the unit of the International Practical Temperature Scale is the kelvin which by definition is the fraction $1 / 273.16$ of the thermodynamic temperature of the triple point of water [2]. The kelvin is abbreviated by the symbol $k$ and is equal to a degree in the Celsius temperature scale. A difference of temperature is expressed in kelvins; it may also be expressed in degrees Celsius.

The six mentioned quantities are the only Basic Standards defined by international agreement, and all other standards are derived from these six. These derived standards are referred to either as Derived Standards or as Reference Standards, and should be preceded by an identification as to whom they belong; hence NBS Reference Standards.

By 1875 the United States was one of 17 countries that signed an international treaty in France, the Metric Convention (today there are 40 countries who are signees). This treaty set up defined metric standards of length and mass, and established the International Bureau of Weights and Measures (BIPM). Also established was the General Conference of Weights and Measures (GCWM), 
which would meet every six years to consider any needed improvements in the standards, and to serve as the authority governing the International Bureau. An International Committee of Weights and Measures (ICWM) was also set up to implement the recommendations of the General Conference, and to direct the activities of the International Bureau: this Committee meets every two years. Figure 1 gives a pictorial display of the relationship of the National Laboratories to the three functioning international organizations, differentiating between the diplomatic and technical levels of activity in the chain.

From figure 1 we can see that the only contact any country has with these international organizations is through their own National Laboratories. This limited contact removes the burden of negotiating agreements in measurements and standards from privately owned industrial concerns when dealing in international trade, and avails them of a means of coordinating results through each of the countries' respective National Laboratories. The burden of coordinating measurements and standards is a concern of these international organizations.

In 1866 the metric system of measurement was established by law to be an acceptable system of measurement in the U.S., and in 1902 an effort to make it the only system of units for Federal usage was defeated in Congress. There are at present only four major countries in the nonmetric world (the United States, Canada, Australia, and New Zealand), and Australia has recently completed a study which recommended conversion to the metric system. Such a move on Australia's part would have a great deal of influence on New Zealand. At present a study is in progress to determine what course of action should be taken in the United States.

In the United States the National Bureau of Standards was designated by a law enacted in 1901 as the sole National Laboratory to represent this country to the international organizations, and to maintain the United States measurement standards. This law when enacted, however, did not carry with it any authority to enforce the use of or reference to these standards. It was left up to individuals and organizations to decide whether they would cooperate with NBS or not.

In October 1968, the International Committee of Weights and Measures approved a new International Practical Temperature Scale. The Committee had been authorized to take this action by the 13th General Conference of Weights and Measures which had met in October 1967 . The new International Practical Temperature Scale of 1968 (abbreviated EIPT-68 in French, and IPTS-68 in Eng1ish) is defined in terms of fixed points and interpolation formulas for specified instruments used to realize the scale. There were iwo main reasons for revising the International Practical Temperature Scale. First, the nationa? laboratories had established national scales for the temperature range $10 \mathrm{~K}$ to $90 \mathrm{~K}$, and these efforts needed to be unified. Second, the Scale had not been revised over the temperature range $-183^{\circ} \mathrm{C}$ to $1063^{\circ} \mathrm{C}$ since its inception in 1927 , and improved gas thermometer measurements showed serious differences between it and the thermodynamic temperatures [2]. The new Scale differs from the previous scale, the International Practical Temperature Scale of 1948 (IPTS-48), in the following ways:

(1) The new scale extends down to $13.8 \mathrm{~K}$; IPTS-48 terminated at $90.18 \mathrm{~K}$.

(2) New values have been assigned to most of the defining fixed points and to the second radiation constant, $\mathrm{C}_{2}$, in order to more closely approximate the thermodynamic temperature scale [3]. 


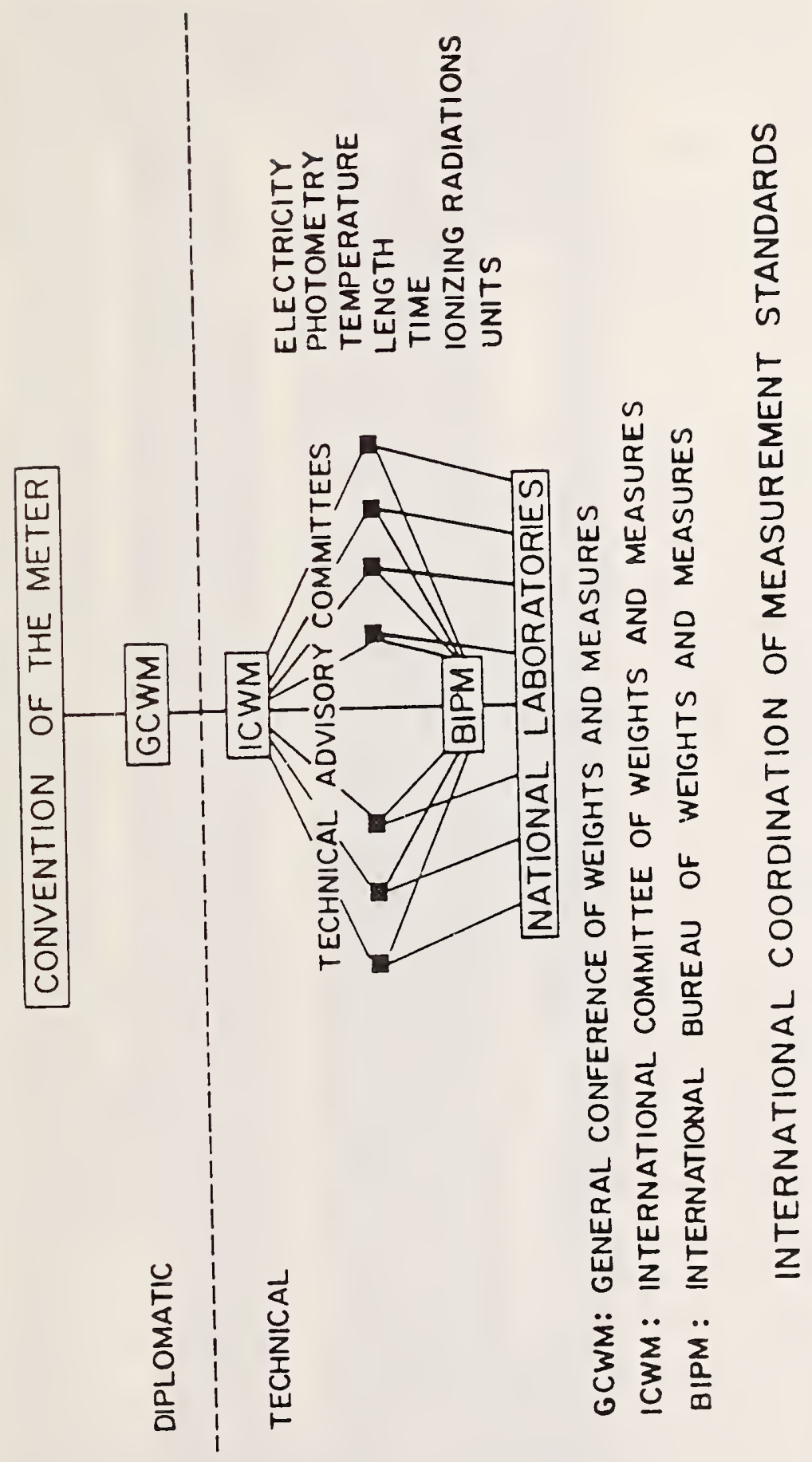


If a Reference Standard is to have the quality of being reproducible, then it must be based on established physical laws and accepted Basic Standards. To satisfy this requirement the measure of thermal noise has been tied into the accepted International Practical Temperature Scale. The second requirement of a Reference Standard is that its physical realization be thoroughly evaluated, both theoretically and experimentally.

\section{THE WR9O AND WR62 REFERENCE NOISE STANDARDS}

Basically the NBS Reference Standards are built about a single concept, but before describing the design a short discussion will establish the fundamentals upon which the designs are based.

\subsection{Fundamentals}

If a resistor that terminates a transmission line is heated to a prescribed temperature, then under ideal conditions the resistor will generate a noise power $P_{n}$ that will be propagated down the transmission line. In this matched and lossless case $P_{n}=k T B$, where $k$ is Boltzmann's constant, $T$ is the temperature of the resistor on the kelvin scale, and $B$ is the limiting bandwidth of the system used to compare the standard to a device under test. Since the bandwidth is constant, the noise power is usually referred to by the temperature of the resistor. Difficulties are quickly encountered however, when a practical model is visualized. The work at NBS to overcome these practical problems is primarily based upon the work done by Wells and his associates $[4,5]$.

\subsubsection{Transmission Line Effects}

Wells sought to 1 ) calculate the noise output of the standard by taking into account both the attenuation and generation effects of the transmission line, and to 2) check the calculated output by building two models in which the parameters were varied in a known way to see if the measurement results obtained were consistent with the calculations. The resulting two transmission lines and resistors were made from different materials, the resistors being formed into different shapes (fig. 2). Results showed that both models gave essentially the same results. The attenuations of the heated waveguide were calculated from dc resistivity values versus temperature. To check the calculations a gold waveguide was constructed and truncated at the heated end, and its reflection coefficient measured with a tuned reflectometer. The measured and calculated values showed remarkable agreement, being well within the estimates of error of measurement and calculation.

This approach calculates both the attenuation effect and the additional noise generated by the transmission line losses. It requires that the resistivity of the material be known as a function of temperature, limiting the number of available materials from which the transmission line can be made. The equation used to calculate the temperature correction to the measured temperature of the resistor for the transmission line effects and its contribution to the error are included in Appendix A. 


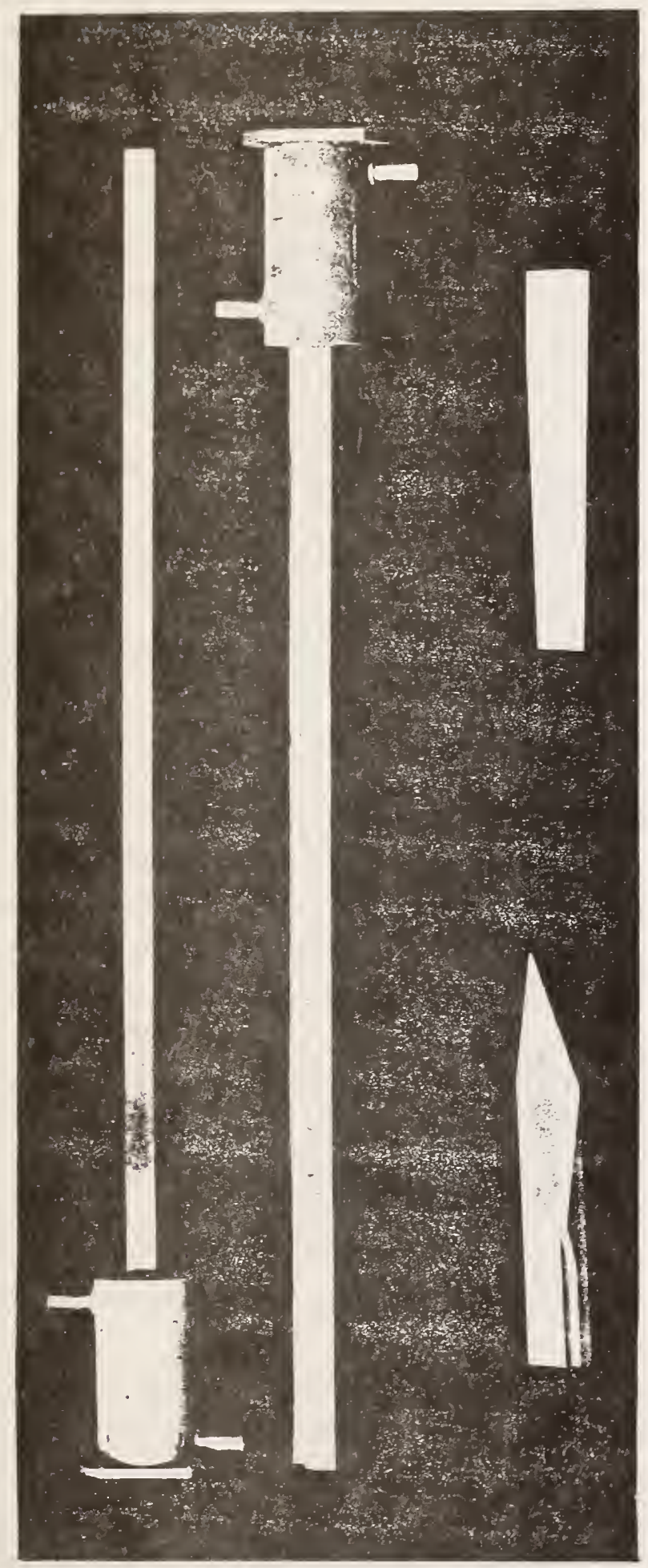

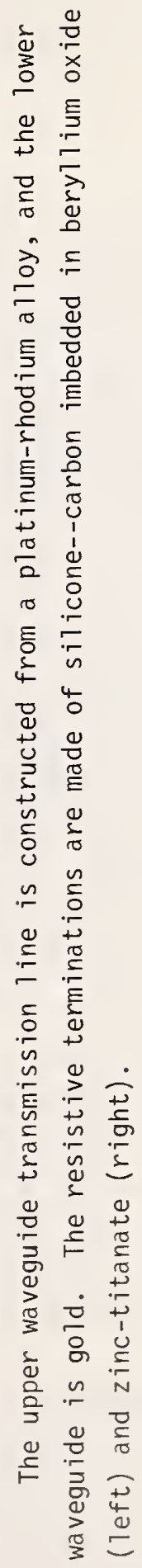




\subsubsection{Resistor Design}

Two different shapes (fig. 2) for the design of the microwave resistor were used, both of which had low reflection coefficients. They were made from lossy materials especially chosen to be compatible with the material of the transmission lines. Since noise radiated from a surface is a volume effect, the spear-pointed shaped resistor had the advantage that three thermocouples could be located in the material along the entire length of the noise generating volume.

\subsubsection{Oven Design}

The requirements of each reference standard necessitates that: 1) a uniform heat input be supplied about the microwave resistor to maintain the gradient of the resistor to less than onehalf kelvin; 2) a designated temperature setting for the resistor be maintainable to less than 0.1 kelvin during 24 hours, and to less than 0.2 kelvin for a week; 3 ) the gradient established for the designated temperature in the transmission line must be held constant -- this requirement is fairly easily accomplished if heat input is uniform and fairly constant and the hot and cold ends of the transmission line are maintained at constant temperatures; and 4) the heating and cooling rates for the oven must be low enough to avoid cracking the heat distributor during heating and cooling the oven.

The oven design (fig. 3 ) is a simple muffle type furnace which has three nichrome heating coils wrapped about a dense, non-porous, high-purity alumina tube that extends through the length of the oven. The larger central heating coil is servo-controlled, and the other two smaller coils are controlled manually. The central heating coil is controlled by a proportional network that selects a portion of each half cycle of the full wave rectified line voltage as the heating duty cycle (phase controlling a silicon-controlled rectifier). A emf from a thermocouple located on the inside surface of the alumina tube serves as the sensing element. The central heating coil is further controlled by a fail-safe device to protect from over-heating in the event of a malfunctioning thermocouple, and by a programmable device to raise and lower the temperature at a set rate.

Inside the alumina tube and centrally located is a dense high-purity beryllia cylinder which serves as a heat distributor. The beryllia cylinder has a rectangular hole into which is placed the microwave resistive generator mounted in one end of the transmission line. Alumina insulators are located in the tube to support the transmission line and thermocouple leads. Figure 4 shows the thermocouple leads extending out of one end of the oven, and the water-cooled flanged end of the transmission line extending out at the front end. The whole control system is located in the base.

An apparent disadvantage to using beryllia as a heat-distributor is its toxicity. The hardfired beryllia heat distributor has been evaluated for toxic dust that could be airborne by vaporization at the surface and, although air samples did indicate the presence of such dust in the vicinity of the operating oven, the traces observed were generally about $1 / 20$ the safe limits (at worst $1 / 10$ the safe limits, and that only for the ovens operated close to the gold point $1064.43^{\circ} \mathrm{C}$ ). The proven safe limit by the AEC is designated to be $2 \mu \mathrm{g}$ per cubic meter of air for persons exposed to beryllia dust for an average 8-hour working day. At this time beryllia heatdistributors are used in this connection at NBS, and have been regularly employed in their role with reference standards for over five years without incident. The advantage to using beryllia is 


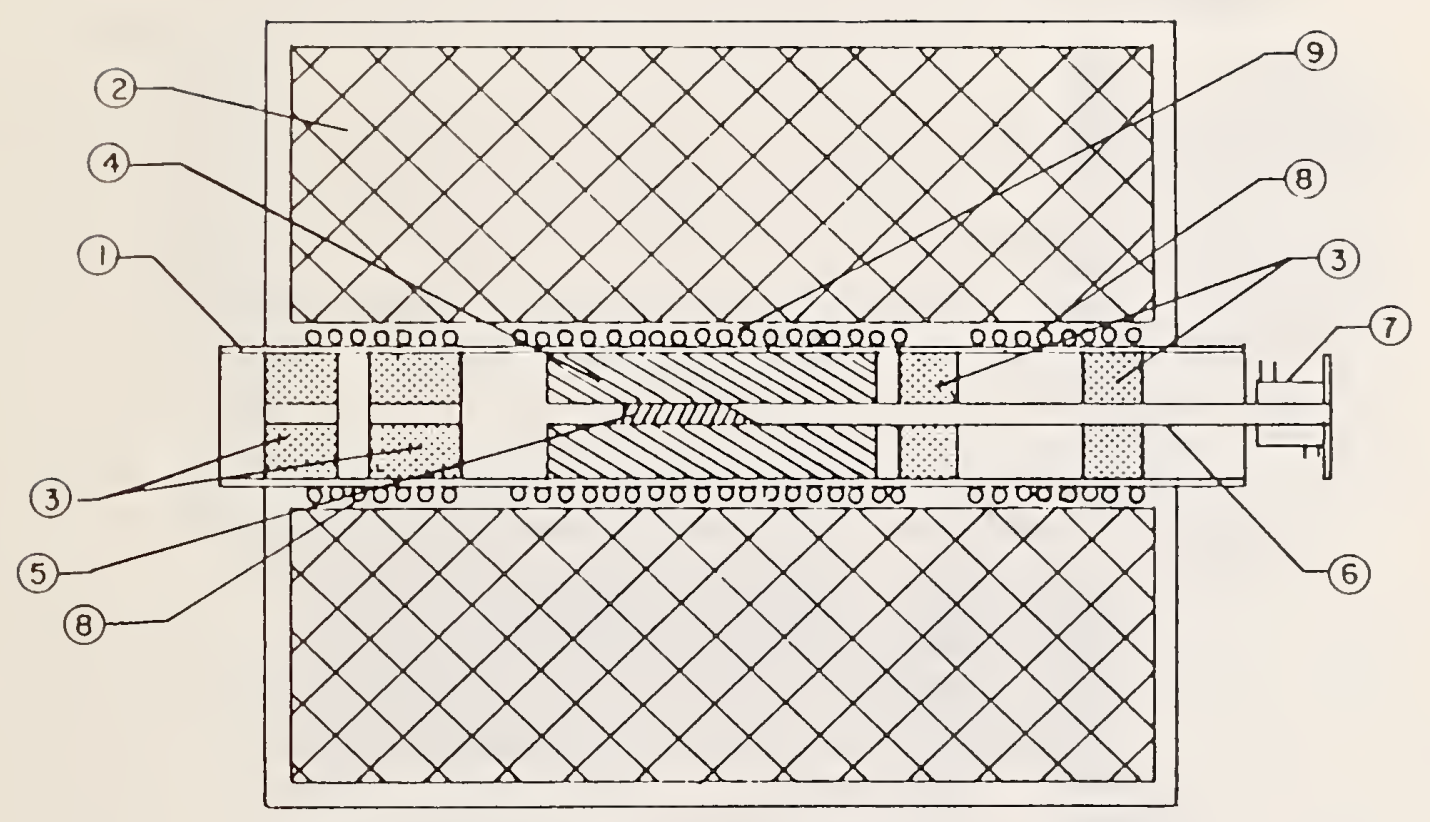

1. ALUMINA TUBE (NON-POROUS)

2. REFRACTORY MATERIAL

3. INSULATORS OF HIGH PURITY

4 HEAT DISTRIBUTOR

5. RESISTIVE MATERIAL WEDGE(NOISE GENERATOR)

6. WAVEGUIDE

7. WATER JACKET ATTACIEO TO FLANGE

8. MANUALLY CONTROLLEO MEATING COILS

9 SERVO-CONTROLLEO HEATING COIL

Figure 3. 


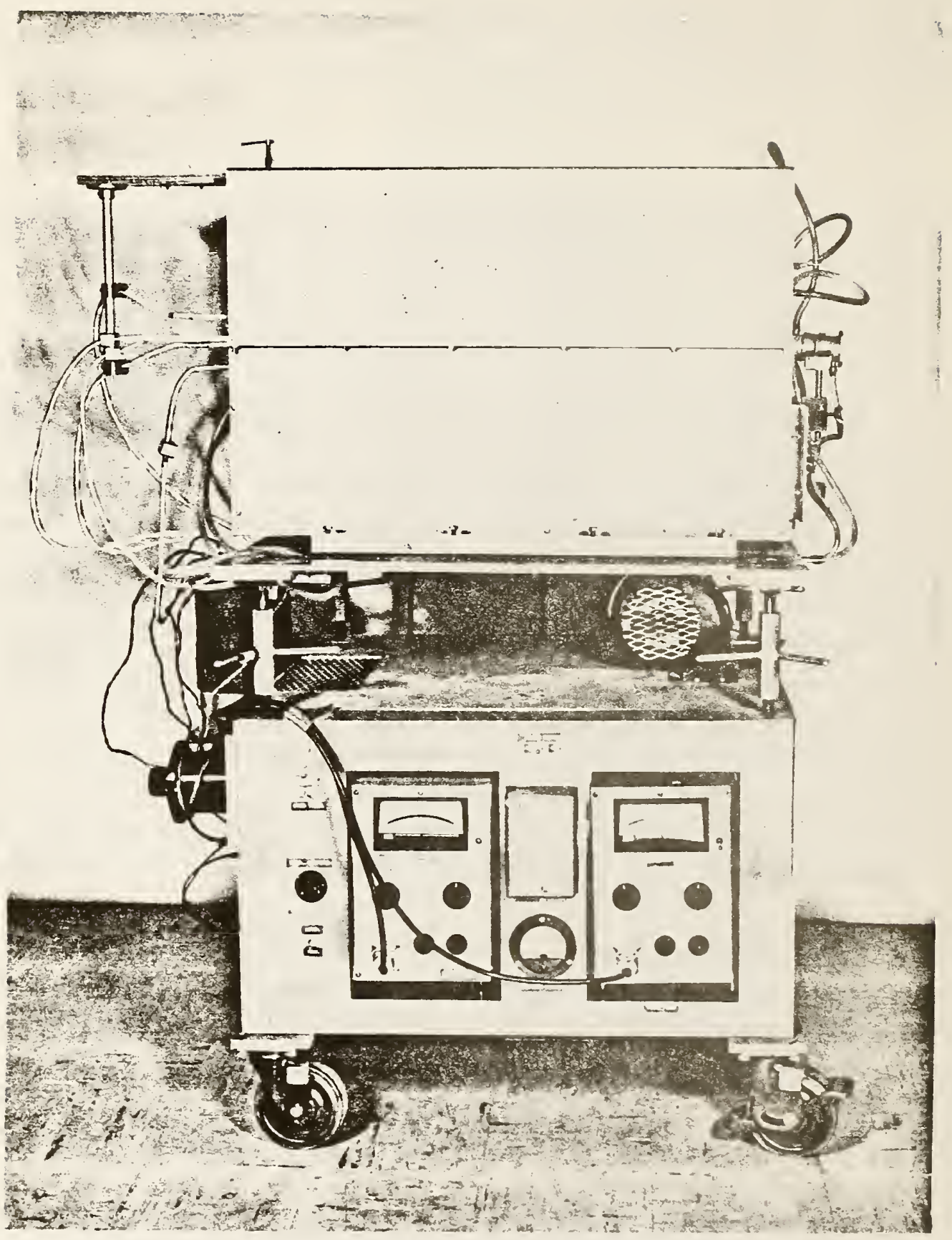

Figure 4. 
its high thermal conductivity, thereby maintaining a uniform temperature in the proximity of the microwave resistive generator -- in addition variations in the heat input from the heating coils are damped out.

\subsection{Application to the WR90 and WR62 Reference Standards}

These two reference standards are quite similar (the major difference is in the size of waveguide employed), so they will be considered together. The description is based on the WR90 model, remarks being injected where the WR62 model is sufficiently different to warrant comment.

\subsubsection{The Waveguide Transmission Line}

Both pure gold and an 87 percent platinum -- 13 percent rhodium alloy for the waveguides were used; the resistivity of both materials has been determined as a function of temperature [4]. For a permanent reference standard it was found that gold was unsatisfactory because: 1) it was too soft and easily distorted, especially at elevated temperatures; 2) when operated within 60 kelvins of its melting point for an extended period of time it is prone to recrystallization and therefore a change in its resistivity; and 3) for the WR90 waveguide size gold was not available in an extruded waveguide form -- an extruded waveguide is commercially available in the WR62 waveguide size. Due to the dissatisfaction with gold both the WR90 and WR62 reference standards use only the platinum alloy waveguide at this time.

The platinum alloy waveguide is approximately $51 \mathrm{~cm}$ long, and has a water-jacket constructed onto its flange to maintain the flange at approximately room temperature $(297 \mathrm{~K})$; this is the output flange of the reference standard. The microwave resistor is inserted into the other end of the waveguide and is operated at about $1273 \mathrm{~K}$. The controlled and manually operated heating coils are set for a minimal gradient in the microwave resistor (the gradient of the resistor must be less than $0.5 \mathrm{~K}$ ). With the heat input and the heat output maintained at a constant rate a steadystate condition is established, and a set gradient exists between the hot and cold ends of the waveguide that can be maintained for long periods of time.

When the gradient is set, it is measured by inserting a calibrated platinum versus platinum 10 percent rhodium thermocouple (the gradient thermocouple) through the output port. Figure 5 shows a typical gradient for the platinum alloy waveguide. Using the tip of the resistor as a zero point, the gradient thermocouple is withdrawn by $2.5 \mathrm{~cm}$ increments; each increment including initial and ending points in the waveguide are measured to $\pm 0.16 \mathrm{~cm}$. Each location that a temperature measurement is made is a difference measurement relative to its preceding measurement, and these difference measurements can be made to $\pm 0.1 \mathrm{~K}$. Since the gradient of the waveguide is started at the tip of the resistive generator, the temperature measurement at this location is an absolute measurement and this measurement is made to $\pm 0.3 \mathrm{~K}$, the accuracy to which the thermocouple is calibrated. The gradient curve is dependent upon the temperature measurements, and if these measurements are not carefully made, this gradient can be upset, causing an error in the output calculation.

For the calculation of the attenuation and noise generation effects of the waveguide and the errors associated with this calculation, the resistivity values are assumed to be in error by less than \pm 20 percent. 

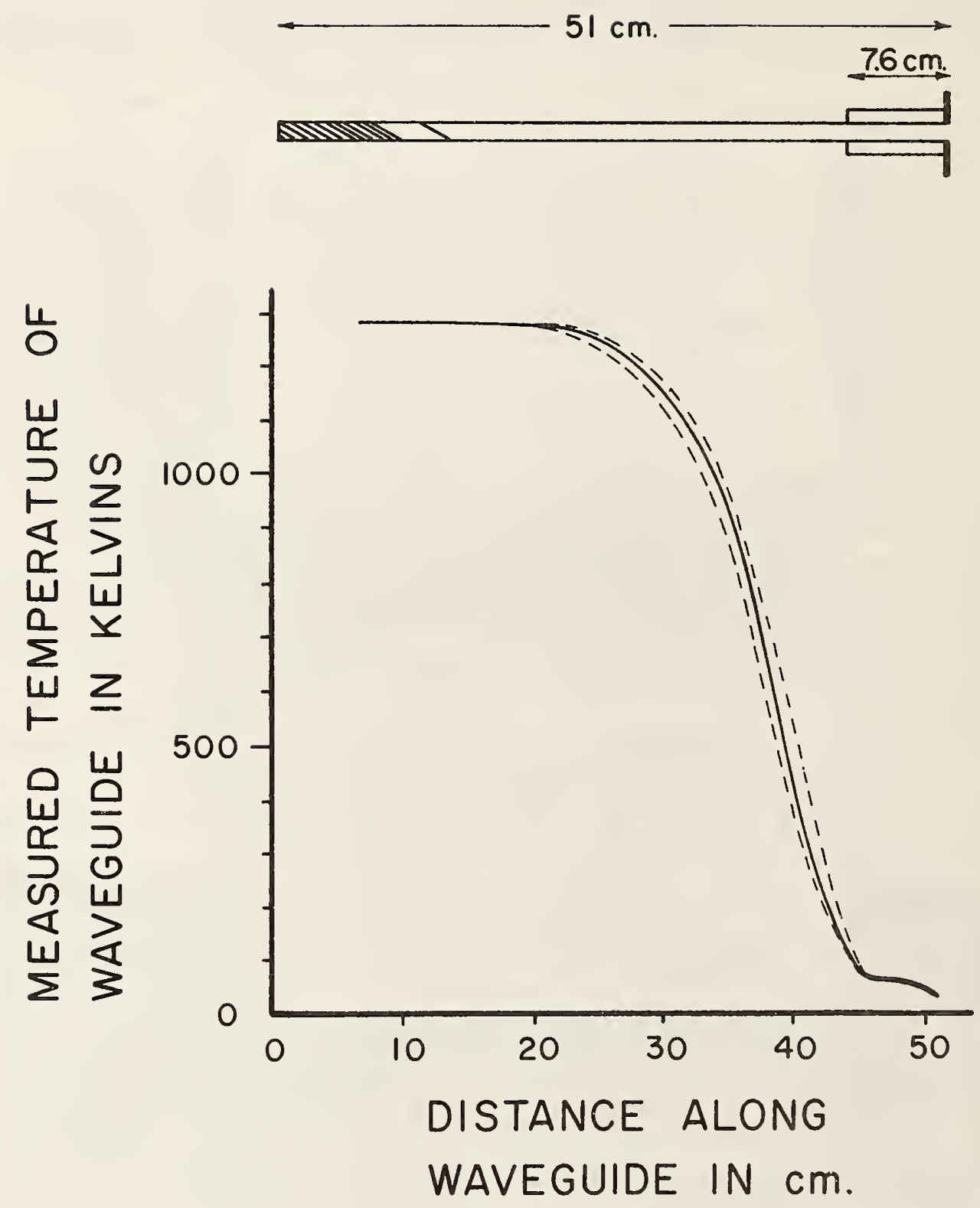

Figure 5. 
The resistive generator is fabricated from a ceramic formed by imbedding silicon-carbide in beryllium-oxide. The material has the good thermal properties of beryllia and the electrically lossy qualities of silicon-carbide.

The shape is experimentally determined by a cut-and-try process with a cheap substitute that at room temperature has comparable characteristics to the Carberlox at elevated temperatures. The shape is intended to give a low reflection coefficient magnitude across the band. Placing the thermocouples initially was done more as a matter of convenience to the designed shape, but their placement has proved very satisfactory.

Using the gradient thermocouple a check is made of the thermal gradient on the resistor's exposed surface (or face) to correlate the temperatures recorded by the three thermocouples imbedded in the resistor with the measured surface temperatures. Two restrictions imposed on these gradient measurements are: 1 ) the temperature gradient of the exposed surface must be less than $0.5 \mathrm{~K}$; and 2) the greatest discrepancy between the three imbedded thermocouples cannot exceed $0.5 \mathrm{~K}$. Both of these restrictions must be met before the reference standard is usable. Using a pyrometer to determine the gradient on the face is not satisfactory since the sensitivity of pyrometers is not adequate.

Figure 6 gives an idea of the temperature conditions found in a typical set of WR90 resistor measurements (the numerical values are very similar to the WR62 resistor). The largest gradient is usually between the tip temperature $T_{F T}$ and the imbedded tip thermocouple temperature $T_{T}$. The exposed surface temperatures are generally about $0.4 \mathrm{~K}$ cooler than a plane parallel to the face that includes the imbedded thermocouples. The error in assuming the whole resistor to be at the temperature $T_{m}$ is $\Delta T_{m}$ and must be determined.

The noise contribution from the region about $T_{B}$ is negligible in determining either $T_{m}$ or $\Delta T_{m}$; this implies that temperatures measured at $T_{b}$ are necessary only to insure that the gradients are minimized. The contribution to the error from temperatures $T_{C}$ and $T_{T}$ is half the difference between them; since $\left|T_{C}-T_{T}\right|<0.5 \mathrm{~K}$, we can assume this portion of the error will always be less than $\pm 0.25 \mathrm{~K}$. The amount of noise generated at the tip of the resistor will be small since the mass is small, so we assume an additional error of $1 / 2 \quad\left|T_{T}-T_{F T}\right|= \pm 0.4 \mathrm{~K}$. The sum of these two effects $( \pm 0.25 \mathrm{~K})+( \pm 0.4 \mathrm{~K})= \pm 0.65 \mathrm{~K}$ encompasses most of the thermal gradient in the resistor (the shaded portion in fig. 6). All thermocouples are calibrated by the Heat Division, NBS, Gaithersburg, Maryland, to a reported accuracy of $\pm 0.3 \mathrm{~K}$. Adding the thermocouple accuracy to these effects gives $\Delta T_{m}<1 K$.

\subsubsection{Accuracy of the WR90 Standard}

The Appendix gives a convenient variation of eq (1) [4] that is programmed for a computer. The computer program also includes an error analysis of the same equation, so that an indication of the contributions of the component errors are read out with the output data. The input data for the program, besides the previously discussed sources of error, are the measured thermal gradient of the waveguide, the constants related to the frequencies selected for operation of the reference standard [4], and the measured temperature of the microwave resistive generator $T_{m}{ }^{\circ}$ For an actual measured gradient of the waveguide, table 1 shows the comparative results of input and output data. The values in table 1 are unique to the gradient; since the gradient will change with each 


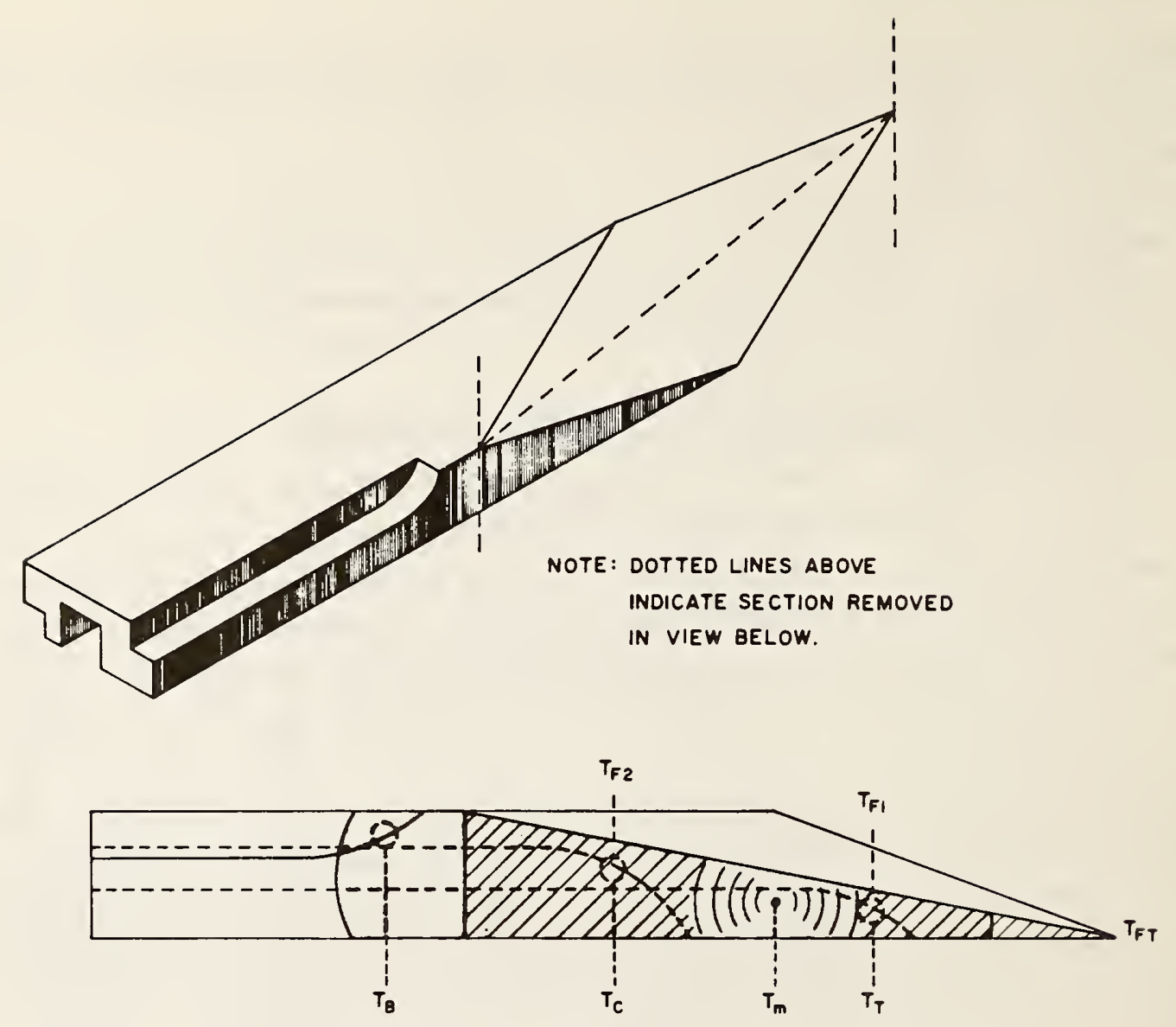

Yeasured Data

$$
\begin{array}{ll}
\left|\mathrm{T}_{\mathrm{T}}-\mathrm{T}_{\mathrm{FT}}\right| \simeq 0.8 \mathrm{k} & \left|\mathrm{T}_{\mathrm{B}}-\mathrm{T}_{\mathrm{T}}\right|<0.5 \mathrm{k} \\
\left|\mathrm{T}_{\mathrm{C}}-\mathrm{T}_{\mathrm{F} 2}\right| \simeq 0.4 \mathrm{k} & \left|\mathrm{T}_{\mathrm{C}}-\mathrm{T}_{\mathrm{T}}\right|<0.5 \mathrm{k} \\
\left|\mathrm{T}_{\mathrm{T}}-\mathrm{T}_{\mathrm{F} 1}\right| \simeq 0.4 \mathrm{k} & \left|\mathrm{T}_{\mathrm{B}}-\mathrm{T}_{\mathrm{C}}\right|<0.5 \mathrm{k}
\end{array}
$$

Accuracy Determination

$$
\begin{aligned}
\mathrm{T}_{\mathrm{m}} & =\frac{{ }^{\mathrm{T}} \mathrm{C}+\mathrm{T}_{\mathrm{T}}}{2} \\
\Delta \mathrm{T}_{\mathrm{m}} & = \pm\left[\frac{\left|\mathrm{T}_{\mathrm{C}}-\mathrm{T}_{\mathrm{T}}\right|}{2}+\frac{\left|\mathrm{T}_{\mathrm{T}}-\mathrm{T}_{\mathrm{F} \cdot \mathrm{T}}\right|}{2}+\Delta \mathrm{T}_{\mathrm{Calib}}\right] \\
& = \pm[(0.25)+(0.4)+(0.3)]< \pm 1.0 \therefore
\end{aligned}
$$

Therefore, $T_{m} \pm \Delta T_{m}$ is shown by shaded area.

Figure 6. 
Table 1.

FOR A GIVEN WAVEGUIDE GRADIENT AT $9.6 \mathrm{GHz}$, THE SOURCES OF ERROR OF THE WR9O NBS REFERENCE STANDARD ARE:

Measured Temperature of Resistor $T_{m}=1275.6 \mathrm{~K}$

Input Data

Resulting

Error in Standard

The Error in Knowing the Absolute Temperature of the Microwave

Resistive Generator

$1.00 \mathrm{~K} \quad 0.96$

Error in Establishing Zero Point for Length Measurement

$0.16 \mathrm{~cm}$

0.04

Error in Establishing Each Inch

Increment of Length--This is

Cumulative to the Whole Length

$0.16 \mathrm{~cm}$

1.63

Error in Establishing the End Point for the Total Length Measurement

$0.16 \mathrm{~cm}$

0.23

Error in Difference Temperature Measurements for Each Increment of Length

$0.1 \mathrm{~K}$

0.03

Error Due to Assuming Resistivity

Values of Waveguide to be

Inexact

$20 \%$

0.02

Total Error for NBS Reference Standard

At $9.6 \mathrm{GHz}$

2. 91

The Correction to $T_{m}$ Due to the Waveguide Gradient $=-13.05 \mathrm{~K}$

operation (extreme gradients are shown by dotted lines in fig. 5) the resulting accuracy will also change. Generally, for a given fixed gradient the accuracy is poorer at the lower frequencies in the band. It should be noted that changes in frequency will affect the contributions from each source error identified in table 1 influenced by the gradient in the waveguide, while the error of the resistive generator $\Delta T_{m}$ does not change.

The correction to the measured temperature of the resistive generator due to the influence of the waveguide loss is also calculated by the computer, and for $9.6 \mathrm{GHz}$ amounted to a negative 13.05 kelvins as shown in table 1 . This in turn implies that of the microwave noise generated by the resistor only $\left(T_{m}-13.05\right)$ is available at the output flange of the standard.

\section{COMPARISON OF REFERENCE STANDARDS}

There are several countries that have either developed or purchased their own standards. Intercomparing these standards assures a degree of measurement agreement between countries. 
NBS has been a partner to three international comparisons in WR90 waveguide. Unfortunately, to compare reference standards the outputs of the standards have been compared to an argon gasdischarge noise source having a noise output that is a great deal higher than the reference standards. This implies that the errors due to transferring the noise output of the reference standard to the argon source are part of the comparison error. A degradation of accuracy occurs in this transfer, and this in turn implies that an evaluation of the comparison radiometers must be made. Evaluation of the radiometers differs not only with the mode of operation and design, but also with the experience of the respective metrologists. Some of the difficulties would be eliminated if the noise power of an argon noise source were attenuated to the level of the reference standards of concern, as was once suggested [6]. With interlaboratory standards of comparable noise output to the reference standards being intercompared, errors could be reduced \pm 15 kelvins and the results would be independent of most of the effects of the comparison radiometers used.

\subsection{International Comparison with Sweden}

In January 1965 an intercomparison was initiated with the Swedish national laboratory, the Research Institute of National Defense (FOA) at Stockholm. The FOA WR90 Reference Standard was fabricated for them by a Japanese firm and is designed to operate at $1000 \mathrm{~K}$, and their radiometric comparator was fabricated by a U.S. firm [7]. The reference standard and the radiometer are each capable of $\pm 0.05 \mathrm{~dB}$ accuracy. Therefore, the comparison measurements of argon noise sources with outputs of about $11,000 \mathrm{~K}$ is estimated by $F 0 A$ to be $\pm 0.1 \mathrm{~dB}$.

At the time of this comparison all of the sources of error were not known at NBS, but it was felt that a conservative estimate of the total error was $\pm 0.1 \mathrm{~dB}$. FOA sent NBS three waveguide noise sources (argon) directly from the manufacturer. The three were measured in January 1965. Two of the three were compared to the NBS WR90 Reference Standard indirectly by way of using the NBS Working Standards, and one was compared directly. The reference standard used was the gold waveguide with a silicon-carbide resistive generator. In June 1965 the results of the Swedish measurements on the same units were received [8].

In May 1966, two of the three waveguide noise sources were returned to be measured a second time. At this time both were compared directly to the NBS WR90 Reference Noise Standard, this time using the platinum alloy waveguide and the Carberlox resistive generator. The results showed a significant difference in noise output at $9.0 \mathrm{GHz}$. An investigation did not reveal the cause for the change. It was not until long afterwards that it was discovered that recrystallization of the gold waveguide used for the comparison in 1965 had been the primary contributor to this discrepancy.

From table 2 (the values are given in Excess Noise Ratio above $290 \mathrm{~K}$ with effective noise temperature for NBS measurements included parenthetically) it can be seen that the agreement achieved at $9.8 \mathrm{GHz}$ and $11.2 \mathrm{GHz}$ never was very good between NBS and FOA although their results are quite self-consistent from one comparison to the next. The large difference between the values measured in 1965 and 1966 by NBS should also be noted. Later FOA learned that a discrepancy was found in the calibration of their temperature measuring thermocouple, and when it was recalibrated their measured values dropped by approximately $0.1 \mathrm{~dB}$, with the final result that now moderately good agreement exists between NBS and FOA. FOA also found some small improvements made to the radiometer improved things on their end. 
Table 2.

Comparison With Sweden

Comparison of January-June 1965 [8]

\begin{tabular}{c} 
9. $0 \mathrm{GHz}$ \\
ENR \\
\hline
\end{tabular}

$9.8 \mathrm{GHz}$
ENR

11. $2 \mathrm{Ghz}$

ENR

NBS Test No. 40020

NBS

$15.77 \mathrm{~dB}$

$15.73 \mathrm{~dB}$

$\left(11,150 \mathrm{~K}^{*}\right)$

$15.75 \mathrm{~dB}$ $\left(11,240 \mathrm{~K}^{*}\right)$

$15.86 \mathrm{~dB}$

$\left(11,190 \mathrm{~K}^{*}\right)$

FOA

$15.80 \mathrm{~dB}$

$15.83 \mathrm{~dB}$

NBS Test No. 40021

NBS

$\begin{array}{rl}15.77 & \mathrm{~dB} \\ \left(11,230 \mathrm{~K}^{*}\right)\end{array}$

$15.74 \mathrm{~dB}$

$\left(11,160 \mathrm{~K}^{\star}\right)$

$15.75 \mathrm{~dB}$

FOA

$15.80 \mathrm{~dB}$

$15.86 \mathrm{~dB}$

$\left(11,190 \mathrm{~K}^{*}\right)$

NBS Test No. 40022

NBS

$15.78 \mathrm{~dB}$ $\left(11,260 \mathrm{~K}^{*}\right)$

$15.75 \mathrm{~dB}$ $\left(11,180 \mathrm{~K}^{\star}\right)$

$15.76 \mathrm{~dB}$

$15.83 \mathrm{~dB}$

FOA

$15.80 \mathrm{~dB}$

$15.88 \mathrm{~dB}$ $\left(11,210 \mathrm{~K}^{\star}\right)$

$15.86 \mathrm{~dB}$

Comparison on May-June 1966 [9]

NBS Test No. 40021

NBS

$15.70 \mathrm{~dB}$

$(11,060 \mathrm{~K})$

$15.73 \mathrm{~dB}$

$(11,140 \mathrm{~K})$

$15.74 \mathrm{~dB}$

$(11,170 \mathrm{~K})$

FOA

$15.79 \mathrm{~dB}$

$15.82 \mathrm{~dB}$

$15.83 \mathrm{~dB}$

NBS Test No. 40022

NBS

$15.71 \mathrm{~dB}$

$15.74 \mathrm{~dB}$

$(11,090 \mathrm{~K})$

$(11,170 \mathrm{~K})$

$15.76 \mathrm{~dB}$

$15.81 \mathrm{~dB}$

$15.84 \mathrm{~dB}$

$(11,200 \mathrm{~K})$

FOA

$15.84 \mathrm{~dB}$

$15.86 \mathrm{~dB}$

${ }^{*}$ All effective noise temperature measurements are related to the IPTS -48 temperature scale.

\subsection{International Comparison with England}

In May 1966 an intercomparison was initiated with the Services Value Test Laboratory (SVTL) of England, which serves as the national laboratory in England. A comparison had been initiated in 1964, but the waveguide noise source became unstable and therefore unsuitable for the purpose. The SVTL WR90 Reference Noise Standard operates at $673 \mathrm{~K}$ and was constructed at SVTL [9]. The SVTL radiometric comparator is an IF switched radiometer [9]. The waveguide noise sources containing argon noise tubes used for the comparison were an SVTL design [9] but made commercially in 
England. The evaluation SVTL had made of their reference standard and their radiometer resulted in "an absolute accuracy of $\pm 130 \mathrm{~K}( \pm 0.05 \mathrm{~dB})$ " [9] capability.

In November 1966 NBS received one mount and three argon noise tubes for the comparison. When each tube was placed in the mount it comprised a one-port waveguide noise source to be measured. The repeated removal and reinsertion of the tube in the mount proved to have a good repeatable effective noise temperature. For this reason the results will be referred to by the tube number although the combination of tube in mount is implied in each case. For the NBS measurements the platinum alloy waveguide with the Carberlox resistive generator was used since by this time the gold waveguide had been shelved.

In January 1967 SVTL remeasured the three noise tubes in the same mount and returned them to NBS, who in turn measured them a second time in April 1967. They were returned to SVTL the 1ast time in April where they were remeasured in May and June 1967.

The connectors used in England are different to the type common to the U.S., and SVTL allowed for this by providing a mount that had a UG 39/U cover flange for the convenience of NBS. Therefore, it became necessary for SVTL to account for the adapter loss, which they did by measuring two such adapters back to back, and assuming the loss to be half the loss measured [10].

Table 3 lists the values obtained in the comparison [10], and is recorded in terms of the effective noise temperature $T_{n e}$ (kelvins) and the excess noise ratio ENR $(d B)$. During the course of the comparison SVTL encountered difficulties using a choke flange at $9.8 \mathrm{GHz}$, finding it to have resonances at this frequency. They corrected data accordingly. SVTL also became aware of a deficiency in their calibration method for their precision attenuator. This was eliminated and corrections to the data taken were made. In the end SVTL estimated that the improvements to their measurements system increased the accuracy to $\pm 100 \mathrm{~K}$, or $\pm 0.04 \mathrm{~dB}$ in the ENR. In the interim, no changes or modifications to the NBS equipment or measurement methods were made except that the NBS WR90 Reference Noise Standard was disassembled and reassembled for the second set of measurements with a new set of thermocouples for the resistor temperature measurements. The accuracy NBS claimed was $\pm 135 \mathrm{~K}$, or $\pm 0.05 \mathrm{~dB}$ in the ENR.

Table 3 shows the good agreement achieved in the final results, but does not indicate the original data taken. Several peculiarities are noticeable however. The differences between the SVTL and the NBS measurements show: 1) at 9.0 and $11.2 \mathrm{GHz}$ the values given by SVTL are higher than those by NBS; 2) at $9.8 \mathrm{GHz}$ the values are reversed; and 3 ) the SVTL results indicate an increasing measured value of each waveguide noise source with increasing frequency of operation while the NBS results indicate the highest values were obtained at the center frequency of measurement. It is worth noting that since SVTL uses a resistive generator at $673 \mathrm{~K}$ their values should be increased by approximately 2 kelvins to comply with the IPTS-68 temperature scale while NBS values should be increased by approximately 14 kelvins. This improves the agreement.

\subsection{International Comparison with Australia and Japan}

In 1966 three organizations in Japan had microwave reference standards. They had intercompared these reference standards through the use of a waveguide noise source with an argon tube. Unfortunately they each measured the same waveguide noise sources at three separate frequencies; their results showed little agreement. The University of Tokyo (UT) has a cryogenic reference standard, the Electrotechnical Laboratory (ETL is the national laboratory of Japan for noise) a 
Table 3.

Comparison With England

\begin{tabular}{|c|c|c|c|c|c|}
\hline \multicolumn{2}{|c|}{$9.0 \mathrm{GHZ}$} & \multicolumn{2}{|c|}{$9.8 \mathrm{GHz}$} & \multicolumn{2}{|c|}{$11.2 \mathrm{GHz}$} \\
\hline $\begin{array}{l}T_{n e}{ }^{*} \\
\text { in Kelvin }\end{array}$ & $\begin{array}{c}\text { ENR } \\
\text { in Decibels }\end{array}$ & $\begin{array}{c}T_{\text {ne }}^{*} \\
\text { in Kelvin } \\
\end{array}$ & $\begin{array}{c}\text { ENR } \\
\text { in Decibels }\end{array}$ & $\begin{array}{c}T_{n e}^{*} \\
\text { in Kelvin }\end{array}$ & $\begin{array}{c}\text { ENR } \\
\text { in Decibels }\end{array}$ \\
\hline
\end{tabular}

Tube No. 261

$\begin{array}{ccccccc}\text { SVTL } & 11178 & 15.745 & 11192 & 15.751 & 11234 & 15.763 \\ \text { NBS } & 11160 & 15.738 & 11216 & 15.761 & 11196 & 15.753 \\ \text { SVTL } & 11178 & 15.745 & 11199 & 15.754 & 11228 & 15.765 \\ \text { NBS } & 11150 & 15.734 & 11201 & 15.755 & 11191 & 15.751 \\ \text { SVTL } & 11183 & 15.747 & 11197 & 15.753 & 11230 & 15.766\end{array}$

Tube No. 277

$\begin{array}{lccc}\text { SVTL } & 11213 & 15.759 & 11229 \\ \text { NBS } & 11188 & 15.750 & 11245 \\ \text { SVTL } & 11210 & 15.758 & 11232 \\ \text { NBS } & 11178 & 15.745 & 11240 \\ \text { SVTL } & 11211 & 15.758 & 11229\end{array}$

15.766

15.767

15.766
15.772

15.770
11271

11236

11266

11264
15.782

15.780

15.779
15.768 15.762

Tube No. 302

$\begin{array}{lcccccc}\text { SVTL } & 11336 & 15.808 & 11349 & 15.814 & 11384 & 15.826 \\ \text { NBS } & 11315 & 15.800 & 11370 & 15.821 & 11354 & 15.815 \\ \text { SVTL } & 11334 & 15.808 & 11352 & 15.815 & 11386 & 15.827 \\ \text { NBS } & 11303 & 15.795 & 11368 & 15.821 & 11342 & 15.811 \\ \text { SVTL } & 11335 & 15.808 & 11351 & 15.815 & 11388 & 15.828\end{array}$

*A1l effective noise temperature measurements are related to the IPTS-48 temperature scale.

heated reference standard that is operated at the freezing point of gold, and the Tokyo Electrical Engineering College (TEEC) a heated reference standard.

In March 1967 NBS participated in a comparison with the Japanese and the Commonwealth Scientific and Industrial Research Organization (CSIRO) of Australia. Not much is known of the Japanese reference standards and measurement system. However, the Australian reference standard and radiometric comparator is described by Somlo and Hollway [11]. The Australians used a heated reference standard with the resistive generator operated at $1300 \mathrm{~K}$ [12].

Three frequencies were chosen for this comparison, one each to coincide with each of the frequencies of measurement used by the three organizations in Japan. The results obtained are detailed in table 4 with the respective accuracies indicated with the results. It is worth noting that agreement with University of Tokyo was very good at one frequency only. Apparently, the waveguide noise source stayed quite stable as indicated by the measurements at the University of Tokyo, taken first in September 1966 and again in September 1967. Agreement between NBS and CSIRO was not as good as was expected, being just within the \pm 90 kelvins accuracy limits. At $11.1 \mathrm{GHz}$ the value obtained by CSIRO is in disagreement with the other values reported. Unfortunately, the values obtained at 9.375 and $10.0 \mathrm{GHz}$ are only useful for the comparison between CSIRO and NBS. 
Table 4.

Comparison With Australia And Japan

Date Organization

$\frac{T_{n e}{ }^{*}}{\text { (in Kelvin) }} \quad \frac{\text { ENR }}{\text { (in Decibels) }}$

For $9.375 \mathrm{GHz}$

Sept. 1966

March 1967

Aug. 1967

Sept. 1966

March 1967

Aug. 1967

Sept. 1966

March 1967

Aug. 1967

Sept. 1967
ETL

NBS

CSIRO

TEEC

NBS

CSIRO

UT

NBS

CSIRO

UT
$11,280 \pm 440$
$11,590 \pm 145$
$11,509 \pm 90$

$15.79 \pm 0.16$

$15.907 \pm 0.06$

$15.876 \pm 0.0035$

For $10.0 \mathrm{GHz}$

$11,700 * *$

$11,626 \pm 130$

$11,550 \pm 90$

$15.921 \pm 0.05$

$15.891 \pm 0.035$

For $11.1 \mathrm{GHz}$

*A1l effective noise temperature measurements are related to the IPTS-48 temperature scale.

**This value is unofficial and is only included to give a perspective to the problem in Japan.

\section{REFERENCES}

[1] National Bureau of Standards (U.S.), Special Publication 304, 1968.

[2] "The International Practical Temperature Scale of 1968," Int. Jr. of Sci. Metrology, Vol. 5, No. 2, pp. 35-44, April 1969.

[3] National Bureau of Standards (U.S.), Technical News Bulletin, Vol. 53, No. 1, pp. 12-13, 1969.

[4] Wells, J. S., W. C. Daywitt, and C. K. S. Miller, "Measurement of Effective Temperatures of Microwave Noise Sources," IRE International Conv. Rec. Pt. 3, pp. 220-238, March 1962; also in IEEE Trans. on Instrumentation \& Measurement, Vol. IM-13, pp. 17-28, March 1964.

[5] Miller, C. K. S., W. C. Daywitt, and M. G. Arthur, "Noise Standards, Measurements and Receiver Noise Definitions," Proc. IEEE, Vol. 55, No. 6, pp. 865-877, June 1967.

[6] Miller, C. K. S., W. C. Daywitt, and E. Campbe11, "A Waveguide Noise-Tube Mount for use as an Interlaboratory Standard," Acta IMEKO III, pp. 371-381, 1964.

[7] Liedquist, L., "Absolutkalibrering av bruskallow inom Mikrovagsomradet" ("Absolute Calibration of Noise Sources in the Microwave Field"), Elteknik, Vol. 9, Pt. 3, pp. 43-47, March 1966.

[8] Per-0laf Lundbom, private communication. 
[9] Halford, G. J., "Noise Comparators and Standards for S and X Bands," IEEE Trans. on Instrumentation and Measurement, Vol. IM-15, pp. 310-317, December 1966.

[10] G. J. Halford, private communication.

[11] Somolo, P. I., and D. L. Hollway, "The Australian National Standards Laboratory X-Band Radiometer for the Calibration of Noise Sources," IEEE Trans. on Microwave Theory and Techniques, Vol. MTT-16, No. 9, pp. 664-669, September 1968.

[12] F. J. Lehany, private communication. 
The noise temperatures $T_{S}$ of the WR62 and WR90 thermal standards are calculated from the equation

$$
T_{s}=T_{m}+\Delta T
$$

where $T_{m}$ is the temperature of the resistive element and $\Delta T$ is the correction added to $T_{m}$ to account for losses in the waveguide lead. This correction is

$$
\Delta T=\left(T_{0}-T_{m}\right)\left(1-\alpha_{0}\right)+\int_{0}^{l} T_{x}^{\prime}\left(1-\alpha_{x}\right) d x
$$

where the quantities appearing here are defined in the following diagram.

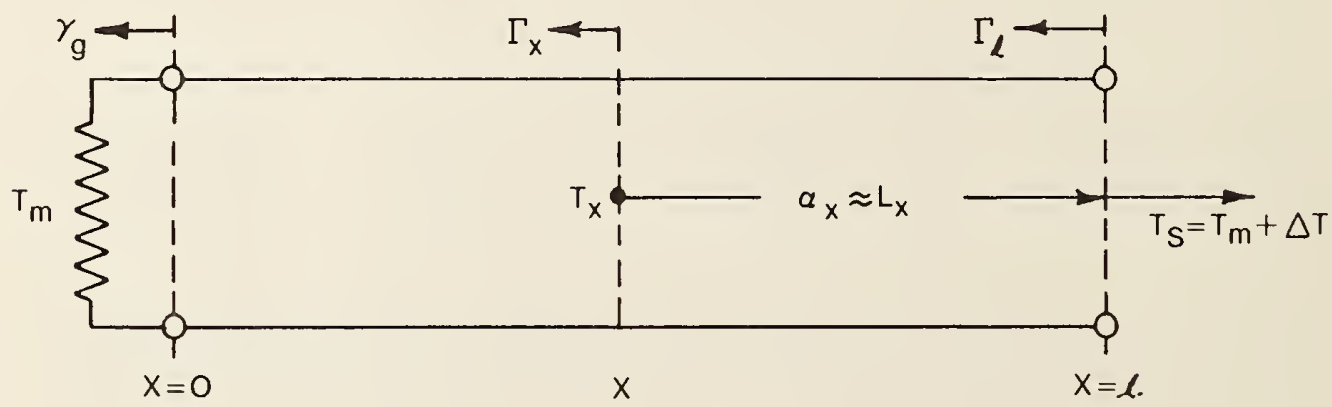

The "waveguide lead" starts a little in front of the resistive element at $x=0$ and extends to $x=\ell$ at the output waveguide flange. The lead is assumed to be uniform and reflectionless, and the point $x=0$ is chosen far enough away from the resistor to be certain higher order modes are absent in the waveguide, but close enough that the waveguide between $x=0$ and the resistor is at approximately the resistor temperature $T_{m} \cdot \Upsilon_{g}$ is the reflection coefficient of the resistor; $\Gamma_{x}$ is the reflection coefficient looking from point $x$ in the line towards the resistor; and $\Gamma_{\ell}=\Gamma_{x=0}$ is the reflection coefficient of the standard. $T_{x}$ is the measured temperature of the line at point $x$ and $T_{x}^{\prime}$ is its derivative with respect to $x . \alpha_{x}$ is the available power ratio of the line from point $x$ to $x=\ell$.

$$
\alpha_{x}=\frac{\left(1-\left|\Gamma_{x}\right|^{2}\right) L_{x}}{1-\left|\Gamma_{\ell}\right|^{2}}
$$

where

$$
L_{x}=10^{-\int_{x}^{\ell} \varepsilon y d y / 10}
$$

$\varepsilon_{y}$ is the attenuation per unit length of the line in $\mathrm{dB}$ per inch, and $y$ is a dummy variable. $\varepsilon_{x}$ is found from a first-order perturbation (in skin depth) calculation [4] and is proportional to 
ine ane-half polwer of the waveguide resistivity. $\varepsilon_{x}$ varies with $x$ because the resistivity is a function of the transmission line temperature.

An approximate expression from $\Delta T$ is used in actual calculations and is given by

$$
\Delta T \simeq\left(T_{0}-T_{m}\right)\left(1-\alpha_{0}\right)+\int_{0}^{\ell} T_{x}^{\prime}\left(1-\alpha_{x}\right) d x
$$

The error incurred from this approximation is negligible, and is given by

$$
\begin{gathered}
\left(T_{0}-T_{m}\right)\left(L_{0}-\alpha_{0}\right)+\int_{0}^{\ell} T_{x}^{1}\left(L_{x}-\alpha_{x}\right) d x \\
\sim 0.5\left|\Gamma_{\ell}\right|^{2}(\Delta)\left(\bar{T}_{\ell}-T_{m}\right)
\end{gathered}
$$

where $\Delta$ is the average total attenuation of the line in $d B$ and $\bar{T}_{\ell}$ is the average line temperature.

The parametric error is $T_{S}$ is found from the equation

$$
\begin{gathered}
\delta T_{s}=\delta T_{m}+\delta \Delta T \\
=L_{0} \delta T_{m}+T_{m} \delta L_{0}+\delta \int_{0}^{l} T_{x} d T_{x}
\end{gathered}
$$

where $\delta T_{m}$ is the uncertainty in $T_{m}$, $\delta L_{0}$ is the uncertainty in the total line attenuation $L_{0}$, and the last term in eq $(A-3)$ arises from uncertainties in actual values of $T_{x}$ and $L_{x}$.

Equations $(A-1),(A-2)$, and $(A-3)$, along with the data on $T_{x}$ and $\varepsilon_{x}$ are fed into a computer for reduction and calculation. The $T_{x}$ data amounts to from fifteen to twenty carefulty measured values of the temperature on the inside surface of the waveguide in one-inch increments from the tip or front face of the termination to the output flange. $\varepsilon_{x}$ is then obtained from a leastsquares-fit curve for the one-half power of tabulated resistivity data over the temperature of interest. The proportionality constant is calculated from the expression given by Wells [4]. 
NBS-114A (REV. 2-8C)

\begin{tabular}{|c|c|c|}
\hline $\begin{array}{c}\text { U.S. DEPT. OF COMM. } \\
\text { BIBLIOGRAPHIC DATA } \\
\text { SHEET (See instructions) }\end{array}$ & $\begin{array}{c}\text { 1. PUBLICATION OR } \\
\text { REPORT NO. } \\
\text { NBSIR } 84-3005\end{array}$ & 2. Performing Organ. Report No.1 \\
\hline 4. TITLE AND SUBTITLE & \\
\hline
\end{tabular}

The NBS WR62 and WR90 Reference Noise Standards

5. $A \cup T H O R(S)$

C.K.S. Miller and W. C. Daywitt

6. PERFORMING ORGANIZATION (If joint or other than NBS, see instructions)

NATIONAL BUREAU OF STANDARDS

DEPARTMENT OF COMMERCE

WASHINGTON, D.C. 20234

7. Contrac/ Grant No.

9. SPONSORING ORGANIZATION NAME AND COMPLETE ADDRESS (Street, City, State, ZIP)

8. Type of Report \& Period Covered

Final 



